\title{
CRESCIMENTO DE PLANTAS MICROPROPAGADAS DE AMOREIRA-PRETA ${ }^{1}$
}

\author{
MARCELO COUTO ${ }^{2}$, LUIS EDUARDO CORREAA ANTUNES 3 , \\ SILVIA CARPENEDO ${ }^{4}$, RENATO TREVISAN ${ }^{5}$
}

RESUMO- A propagação da amoreira-preta pode ser feita através de estacas de raiz, lenhosas ou herbáceas, ou através de técnicas de cultura de tecidos. Entretanto, pouco se sabe sobre o crescimento e desenvolvimento inicial de mudas micropropagadas de amoreira-preta. Sendo assim, o objetivo deste trabalho foi avaliar o desenvolvimento inicial de plantas micropropagadas de amoreira-preta, previamente aclimatizadas, provenientes do laboratório de cultura de tecidos da Embrapa Clima Temperado, Pelotas-RS. O tratamento avaliado foi o fator cultivar, sendo Guarani, Tupy, Xavante e Seleções avançadas 6 e 12, com quatro repetições, sendo cada unidade experimental composta por cinco plantas, 25 plantas por bloco, totalizando 100 plantas. Após 52 dias em casa de vegetação (25-01-2007), as plantas foram retiradas dos sacos de plástico, e tiveram seu sistema radicular lavado e seccionado na altura do colo, sendo avaliadas as variáveis número de folhas altura da parte aérea e comprimento do sistema radicular $(\mathrm{cm})$, medidos do colo ao ápice da maior ramificação e do colo ao ápice da maior raiz, respectivamente e peso da massa fresca e seca da parte aérea e da raiz (g). Nas condições em que o trabalho foi realizado, a seleção 6 e a cultivar Guarani apresentaram, respectivamente, o maior número médio de folhas. $\mathrm{O}$ maior comprimento médio da parte aérea das plantas de amoreira-preta foi observado na cultivar Tupy. Não houve diferença significativa para o comprimento médio do sistema radicular bem como para a massa fresca e seca da parte aérea e do sistema radicular entre as cultivares e seleções avançadas de amoreira-preta.to inicial expexpresso em comprimento de haste e, consequentemente, maior vigor durante esta fase, podendo assim ser indicada como material com maiores possibilidades de sucesso para implantação de um pomar de amoreira-preta em comparação aos demais materiais estudados.

Termos para indexação: Rubus sp., substrato, desenvolvimento inicial, vigor.

\section{GROWTH OF MICROPROPAGATED PLANTS OF BLACKBERRY}

ABSTRACT - The blackberry propagation can be done through root cuttings, woody or herbaceous stem cuttings, or through tissue culture techniques. However, little is known about the initial growth and development of micro propagated blackberry seedlings. The aim of this work was to evaluate the initial development of micro propagated blackberry plants, previously acclimatized, obtained from the laboratory of tissue culture of Embrapa Temperate Climate, Pelotas, Brazil. Three cultivars and two thornless advanced selections (Selection 6 and 12) were evaluated in a randomized block design with four replications and five plants per plot. After 52 days in a greenhouse (01/25/2007), the plants were removed from the plastic bags and had their roots washed and sectioned. The following variables were evaluated; number of leaves; shoot length $(\mathrm{cm})$, measured from the top to the button of the largest branch of the colon; root length $(\mathrm{cm})$ measured from the crown to the longest root apex; fresh and dry weight of shoot and root $(\mathrm{g})$. Under the conditions of this experiment, the selection 6 and cultivar Guarani had, respectively, the highest average number of leaves on $01 / 25 / 07$. The highest average length of the aerial part of the blackberry plants was observed in cultivar Tupy. There was no significant difference on the average length of roots fresh and dry weight of shoots and roots among cultivars and advanced selections of blackberry. Under the conditions of this trial, it can be concluded that cv. Tupy has a higher growth, expressed by cane length. As a result, it has lager vigor during this phase and can be recommended for new blackberries plantings as the cultivar with better chances of success, among all the tested ones, during the present trial.

Index Terms: Rubus sp., substrate, initial development, vigor.

\footnotetext{
1'(Trabalho 067-08). Recebido em: 25-03-2008. Aceito para publicação em: 30-06-2009.

${ }^{2}$ Eng. Agr. D.S. Centro de Pesquisa Agropecuária de Clima Temperado, Caixa Postal 403, CEP 96001-970 Pelotas-RS. Bolsista DTI/ CNPq. e-mail: couto@cpact.embrapa.br

${ }^{3}$ Pesquisador D.S. Centro de Pesquisa Agropecuária de Clima Temperado, Caixa Postal 403, CEP 96001-970 Pelotas-RS. Bolsista PQ/ CNPq. e-mail: antunes@cpact.embrapa.br

${ }^{4}$ Estudante do curso de agronomia, Universidade Federal de Pelotas (UFPel/FAEM), Bolsista CNPq/IC. e-mail: s.carpenedo@hotmail.com; ${ }^{5}$ Eng. Agr., D. S., Bolsista EV/CNPq, Caixa Postal 403, CEP 96001-970 Pelotas-RS. e-mail: renattot@hotmail.com
} 


\section{INTRODUÇÃO}

A produção de amohhreira-preta (Rubus sp.) no mundo ocupa uma área de 20 mil hectares, distribuídos em todos os continentes. Cerca de dois terços da produção são destinados ao processamento, e o restante, ao mercado de frutas frescas (Strik et al., 2007). A amoreira-preta é uma espécie arbustiva de porte ereto ou rasteiro (Crandall, 1995), que produz frutos agregados, com cerca de 4 a 12 gramas de coloração negra e sabor ácido a doce-ácido, possui baixa conservação em pós-colheita (Antunes et al., 2006a). Apresenta espinhos em suas principais cultivares comerciais, o que exige do operador da colheita muito cuidado com sua integridade física, como a da qualidade do fruto. São plantas que produzem em ramos de ano, sendo estes eliminados após a colheita. Enquanto alguns ramos estão produzindo, outras hastes emergem e crescem, renovando o material para a próxima produção (Shoemaker, 1978; Fachinello et al., 1994).

A amoreira-preta é uma das espécies que têm apresentado sensível crescimento de área cultivada nos últimos anos, no Rio Grande do Sul (principal produtor brasileiro), e tem elevado potencial para os demais estados de características climáticas semelhantes (Antunes, 2002; Antunes, 2005; Hoffmann et al., 2005).

A produção brasileira das principais espécies frutíferas de clima temperado é insuficiente para atender à demanda interna, gerando uma crescente necessidade de importação de frutas que podem ser produzidas no Brasil. Tal situação propicia enormes possibilidades de mercado para a produção de frutas frescas e industrializadas, particularmente nos Estados da região Sul, São Paulo e sul de Minas Gerais, principalmente se for considerado que as condições climáticas destas regiões permitem ofertar frutas das espécies de clima temperado por diversos meses no ano (Antunes, 2002).

As maiores produções de amoreira-preta encontram-se nos municípios de Vacaria, Campestre da Serra e Ipê, onde a cultivar Tupy responde por $70 \%$ da área cultivada, com produção a partir do dia 20 de novembro (Hoffmann et al., 2005). Em São Paulo, a produção concentra-se na região de Jundiaí, em Minas Gerais no sul (Planalto de Poços de Caldas) e na Zona da Mata (Barbacena) (Antunes et al., 2000c).

Devido ao baixo custo de implantação, manutenção do pomar, e principalmente a reduzida utilização de defensivos agrícolas, aliada à opção de diversificação da propriedade agrícola nas regiões mais frias do Brasil, esta cultura apresenta-se como uma boa opção de cultivo à agricultura familiar. É um cultivo de retorno rápido, pois já no segundo ano entra em produção, e dá ao pequeno produtor opções de renda, destinando seu produto ao mercado in natura, indústria de produtos lácteos e congelados, e fabrico de geleias caseiras que, com o potencial do ecoturismo regional torna-se bastante atrativo para a agregação de valor ao produto (Antunes et al., 2004). A produtividade pode alcançar até $10.000 \mathrm{~kg} / \mathrm{ha} / \mathrm{ano}$ sob condições adequadas (Antunes et al., 2000a).

Dos trabalhos de melhoramento e introdução de amoreira-preta no Brasil, resultaram várias cultivares recomendadas, com características para industrialização e/ou para o consumo in natura, como Ébano, Negrita, Tupy, Guarani, Caingangue, Xavante, entre outras (Raseira et al., 2004).

A propagação da amoreira-preta faz-se através de estacas de raízes onde estas, por ocasião do repouso vegetativo, são preparadas e enviveiradas em sacolas plásticas. Podem também ser usados brotos (rebentos), originados das plantas cultivadas. O uso de estacas herbáceas é uma das alternativas viáveis. Atualmente, além da propagação tradicional, a micropropagação da amoreira-preta é considerada outra alternativa viável, com o intuito de se obterem plantas livres de vírus, geneticamente uniformes e em curto espaço de tempo (Antunes et al., 2000b; 2004).

Segundo Antunes (2002), trabalhos de melhoramento genético desta frutífera devem ser realizados visando ao desenvolvimento de cultivares sem espinho, com alta produtividade, maior peso de frutos e resistência pós-colheita. As cultivares que não possuem espinhos apresentam maior facilidade de manejo durante as práticas de colheita e seus tratos culturais e, além disso, estas são mais vigorosas que as cultivares de amoreira-preta com espinhos (Hull, 1975), pois a produção de frutos a campo é dependente, em parte, do número, comprimento das hastes e número de gemas (Takeda, 2002).

Neste contexto, o presente trabalho objetivou avaliar o desenvolvimento inicial de plantas micropropagadas de amoreira-preta, previamente aclimatizadas, das cultivares Guarani, Tupy, Xavante e duas seleções avançadas (6 e 12) do programa de melhoramento vegetal da Embrapa Clima Temperado.

\section{MATERIAL E MÉTODOS}

O experimento foi realizado em casa de vegetação da Embrapa Clima Temperado, Pelotas, Rio Grande do Sul (coordenadas geográficas: $31^{\circ} 40^{\prime} 47^{\prime \prime}$ S e $52^{\circ} 26^{\prime} 24^{\prime \prime} \mathrm{W}$; $60 \mathrm{~m}$ de altitude), entre os 
meses de dezembro de 2006 e janeiro de 2007.

Foram utilizadas plantas micropropagadas de amoreira-preta previamente aclimatizadas, das cultivares Guarani e Tupy (com espinhos), Xavante e duas seleções avançadas (6 e 12, sem espinhos), provenientes do programa de melhoramento genético vegetal desta mesma unidade experimental.

As plantas aclimatizadas de amoreira-preta foram transplantadas de bandejas alveoladas de poliestireno, com 72 células, para sacos de plástico de $1 \mathrm{~L}$, quando se procedeu então à contagem do número de folhas por planta (04-12-2006). Foi utilizado o substrato comercial Plantmax ${ }^{\circledR}$, sendo que as plantas foram irrigadas diariamente, durante a condução das atividades experimentais. $\mathrm{O}$ delineamento experimental utilizado foi o de blocos casualizados, com cinco tratamentos (cultivares Guarani, Tupy e Xavante e duas Seleções avançadas-6 e 12) e quatro repetições, sendo cada unidade experimental composta por cinco plantas, 25 plantas por bloco, totalizando 100 plantas.

Após 52 dias em casa de vegetação (25-012007), as plantas foram retiradas dos sacos de plástico e tiveram seu sistema radicular lavado e seccionado na altura do colo, sendo posteriormente avaliadas as variáveis número de folhas, altura da parte aérea e comprimento do sistema radicular $(\mathrm{cm})$, medidos do colo ao ápice da maior ramificação e do colo à ponta da maior raiz, respectivamente, massas fresca e seca da parte aérea e da raiz $(\mathrm{g})$.

Posteriormente, tanto a parte aérea como o sistema radicular das plantas foram colocados em sacos de papel devidamente identificados, sendo imediatamente submetidos à pesagem em balança digital no Laboratório de Melhoramento Genético Vegetal da Embrapa Clima Temperado, para verificar a massa fresca da parte aérea e da raiz. Após 72 horas em estufa a $55^{\circ} \mathrm{C}\left( \pm 2^{\circ} \mathrm{C}\right)$, no Laboratório de Fisiologia Vegetal desta mesma unidade experimental, procedeu-se a nova pesagem do material para determinar a massa seca da parte aérea e da raiz. Os dados foram submetidos à análise de variação, sendo a comparação de médias efetuada pelo teste de Duncan $(\alpha \leq 0,05)$, sendo os dados da variável número de folhas transformados para $(\mathrm{x}+1)^{1 / 2}$.

As análises estatísticas foram executadas pelo programa Winstat, versão 2.0 (Machado e Conceição, 2003).

\section{RESULTADOS E DISCUSSÃO}

Em relação ao vigor das plantas, traduzida pelo comprimento das brotações, a cultivar Tupy obteve o maior crescimento médio $(73,65 \mathrm{~cm})$, seguida da cv. Guarani $(61,30 \mathrm{~cm})$. O pior desempenho em crescimento de ramos foi obtido pela cv. Xavante $(47,20 \mathrm{~cm})$ (Figura 1). Entretanto, essa diferença em crescimento não foi refletida no sistema radicular das plantas, uma vez que não houve diferenças significativas no comprimento de raiz, embora tenha ocorrido uma tendência de a seleção $6(34,81 \mathrm{~cm})$ e Tupy $(34,10 \mathrm{~cm})$ serem superiores (Tabela 1$)$. Estes resultados estão de acordo com as informações citadas por Raseira et al. (2004), que caracterizaram a cv. Tupy como uma planta de amoreira-preta vigorosa.

Apesar do maior crescimento em comprimento de ramos da cultivar Tupy, o maior número médio de folhas foi obtido pela cultivar Guarani $(31,15)$, sendo as demais estatisticamente iguais (Figuras 2). Essa disparidade entre crescimento de ramos e número de folhas, pode ser devida a um maior intervalo entre as gemas (nós) onde estão inseridas as folhas, uma vez que a cv. Tupy, apesar de apresentar o maior comprimento de hastes e Xavante o menor, apresentaram estatisticamente o mesmo número de folhas: 18,95 e 18,85, respectivamente (Figura 2).

Convém salientar que a determinação de parâmetros, como comprimento de ramos e número de folhas no período de crescimento inicial de plantas micropropagadas e previamente aclimatizadas de amoreira-preta, é importante para definir os materiais com maior vigor inicial, os quais, consequentemente, favoreceriam a formação de um pomar com stand de plantas uniformes, antecipando assim a sua entrada em produção. $\mathrm{O}$ número de folhas é uma característica importante e, possivelmente, mudas com maior número de folhas têm maiores índices de pegamento no campo, pois as folhas são as estruturas responsáveis pela captação de energia solar e pela produção de matéria orgânica através da fotossíntese (Sousa, 1994).

Para as características massas fresca e seca da parte área e do sistema radicular, não ocorreu diferença significativa entre as cultivares e seleções avaliadas (Tabela 1). Entretanto, observou-se uma tendência de a cv. Guarani apresentar maior valor de massas fresca e seca da parte aérea $(86,17 \mathrm{~cm}$ e $30,93 \mathrm{~cm})$, respectivamente, que provavelmente pode estar correlacionado ao maior número de folhas obtido nesta cultivar durante a condução do experimento.

As medidas vegetativas de altura da parte aérea, comprimento do sistema radicular, número de folhas e massas fresca e seca da parte aérea e da raiz, associadas às outras medidas produtivas, foram consideradas como essenciais para comparar resultados e estimar vários parâmetros fisiológicos 
de crescimento e produção em plantas de pupunheira (Bactris gasipaes Kunth.) (Clement \& Bovi, 2000). Neste trabalho, pode-se observar que as cultivares Guarani e Tupy, citadas na literatura como sendo mais vigorosas (Raseira et al., 2004), obtiveram melhor desempenho nas suas medidas vegetativas, refletido-se, consequentemente, em plantas mais vigorosas. Este comportamento também foi observado por Antunes et al. (2000b), trabalhando com estacas lenhosas de amoreira-preta, verificaram que a cultivar Caingangue apresentou maior vigor em desenvolvimento que as demais cultivares testadas, refletindo em maior massa seca da parte aérea $(2.060 \mathrm{mg})$ e da raiz $(660 \mathrm{mg})$.
Além disso, conforme Crandall (1995), ocorrem grandes diferenças na frutificação e no hábito de crescimento entre cultivares de amoreira-preta, afirmação que pode auxiliar na compreensão dos resultados obtidos no presente estudo, visto que foram observadas diferenças no crescimento inicial das plantas através das variáveis analisadas. Sendo assim, pesquisas sobre amoreira-preta são importantes para subsidiar o desenvolvimento e a expansão de técnicas para sua domesticação, seleção, cultivo e manejo, favorecendo, assim, o aumento da produtividade e, por conseguinte, o desenvolvimento de novas formas de aproveitamento e comercialização de produtos e subprodutos desta espécie.

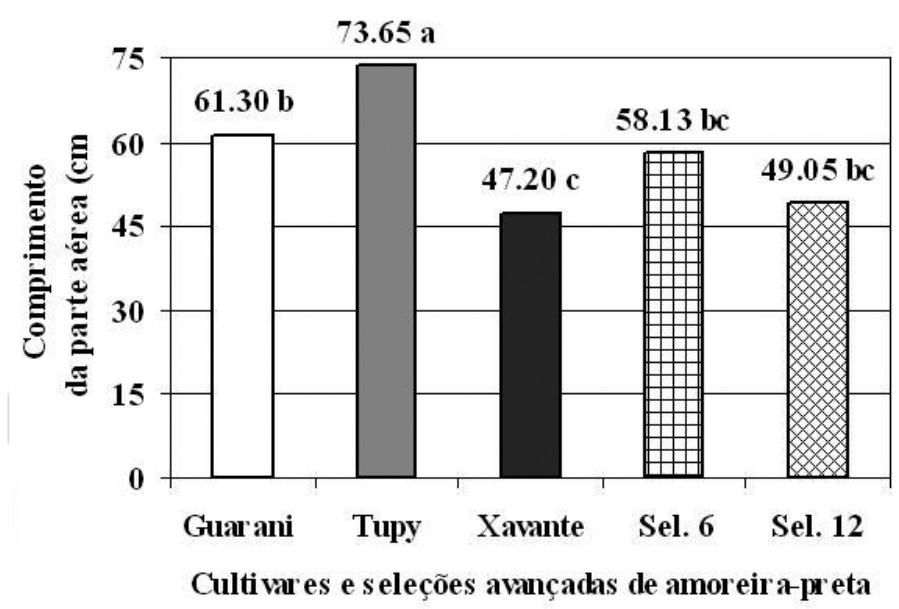

FIGURA 1 - Comprimento médio da parte aérea $(\mathrm{cm})$ de plantas das cultivares e seleções avançadas de amoreira-preta. Embrapa Clima Temperado, Pelotas- RS, 2007. Médias seguidas de mesma letra não diferem entre si, pelo teste de Duncan, a $5 \%$ de probabilidade.

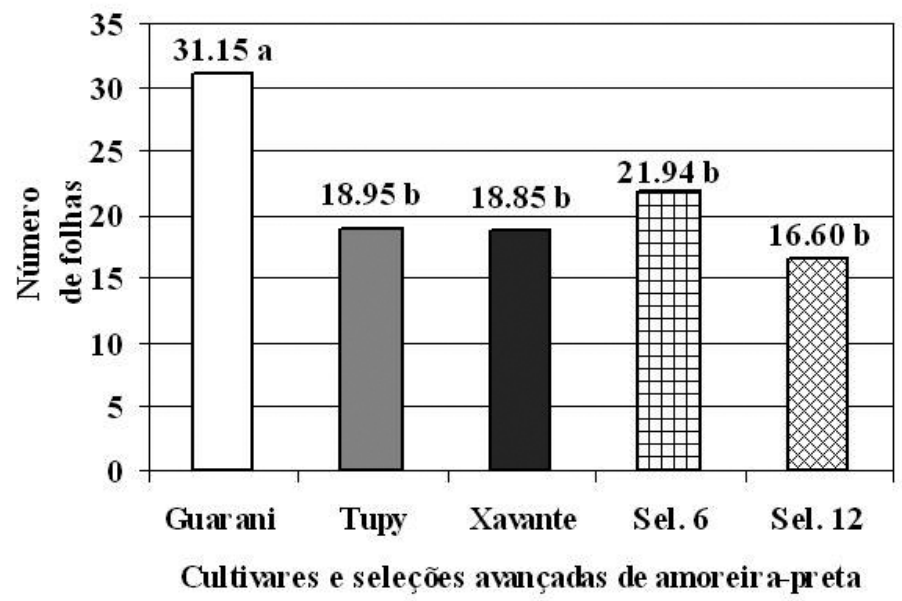

FIGURA 2 - Número médio de folhas de plantas das cultivares e seleções avançadas de amoreira-preta. Embrapa Clima Temperado, Pelotas-RS, 2007. Médias seguidas de mesma letra não diferem entre si, pelo teste de Duncan, a 5\% de probabilidade. 
TABELA 1 - Número médio de folhas em 04-12-2006 e 25-01-2007, comprimento médio da parte aérea do sistema radicular $(\mathrm{cm})$ e médias de massas seca e fresca da parte aérea e do sistema radicular (g) de plantas de três cultivares e duas seleções avançadas de amoreira-pretra. Embrapa Clima Temperado, Pelotas-, 2007.

\begin{tabular}{lccccccc}
\hline $\begin{array}{c}\text { Cultivares/ } \\
\text { Seleçóes }\end{array}$ & $\begin{array}{c}\text { Número } \\
\text { de folhas }\end{array}$ & \multicolumn{2}{c}{$\begin{array}{c}\text { Comprimento } \\
\text { (cm) }\end{array}$} & \multicolumn{2}{c}{ Massa fresca (g) } & \multicolumn{2}{c}{ Massa seca (g) } \\
\hline & $\mathbf{2 5 / 0 1 / 0 7}$ & PA & SR & PA & SR & PA & SR \\
\hline Guarani & $31,15 \mathrm{a}$ & $61,30 \mathrm{~b}$ & $33,30 \mathrm{a}$ & $86,17 \mathrm{a}$ & $43,92 \mathrm{a}$ & $30,93 \mathrm{a}$ & $11,33 \mathrm{a}$ \\
Tupy & $18,95 \mathrm{~b}$ & $73,65 \mathrm{a}$ & $34,10 \mathrm{a}$ & $82,31 \mathrm{a}$ & $44,01 \mathrm{a}$ & $30,46 \mathrm{a}$ & $13,05 \mathrm{a}$ \\
Xavante & $18,85 \mathrm{~b}$ & $47,20 \mathrm{c}$ & $30,85 \mathrm{a}$ & $77,05 \mathrm{a}$ & $40,92 \mathrm{a}$ & $25,54 \mathrm{a}$ & $11,01 \mathrm{a}$ \\
Sel. 6 & $21,94 \mathrm{~b}$ & $58,13 \mathrm{bc}$ & $34,81 \mathrm{a}$ & $72,66 \mathrm{a}$ & $45,57 \mathrm{a}$ & $24,79 \mathrm{a}$ & $12,99 \mathrm{a}$ \\
Sel. 12 & $16,60 \mathrm{~b}$ & $49,05 \mathrm{bc}$ & $28,60 \mathrm{a}$ & $78,55 \mathrm{a}$ & $40,22 \mathrm{a}$ & $26,52 \mathrm{a}$ & $13,58 \mathrm{a}$ \\
\hline MG & 21,50 & 57,86 & 32,33 & 79,34 & 42,93 & 27,65 & 12,39 \\
CV (\%) & 8,36 & 13,15 & 12,99 & 20,21 & 18,93 & 17,79 & 18,67 \\
DP & 3,90 & 7,61 & 4,20 & 16,04 & 8,13 & 4,92 & 2,31 \\
\hline
\end{tabular}

Médias seguidas de mesma letra entre cultivares e seleções avançadas de amoreira-preta não diferem entre si, pelo teste de Duncan, a $5 \%$ de probabilidade;

PA: parte aérea; SR: sistema radicular; MG: média geral; CV: coeficiente de variação (\%); DP: desvio-padrão.

\section{CONCLUSÃO}

Nas condições em que foi realizado o presente trabalho, conclui-se que a cultivar Tupy apresenta maior crescimento inicial expresso em comprimento de haste e, consequentemente, maior vigor durante esta fase, podendo assim ser indicada como material com maiores possibilidades de sucesso para implantação de um pomar de amoreira-preta em relação aos demais materiais estudados.

\section{REFERÊNCIAS}

ANTUNES, L.E.C. Potencial de produção de pequenas frutas em diferentes regiões do sul do Brasil. In: ENCONTRO NACIONAL DE FRUTICULTURA DE CLIMA TEMPERADO, 8., 2005, Fraiburgo. Anais.... Caçador: Epagri, 2005. p. 61-62.

ANTUNES, L.E.C. Amora-preta: nova opção de cultivo no Brasil. Ciência Rural, Santa Maria, v.32, n.1, p.151-158, 2002.

ANTUNES, L. E. C.; GONÇALVES, E. D.; TREVISAN, R. Alterações de compostos fenólicos e pectina em pós-colheita de frutos de amora-preta. Revista Brasileira de Agrociência, Pelotas, v. 12, n. 1, p. 57-61, 2006a.

ANTUNES, L. E. C.; GONÇALVES, E. D.; TREVISAN, R. Alterações da atividade da poligalactutonase e pectinametilesterase em amora-preta (Rubus spp) durante o armazenamento. Revista Brasileira de Agrociência, Pelotas, v. 12, n. 1, p. 63-66, 2006 b.

ANTUNES, L.E.C.; TREVISAN, R.; GONÇALVES, E.D. Propagação, plantio e tratos culturais. In: ANTUNES, L.E.C.; RASEIRA, M.do C.B. Aspectos técnicos da cultura da amora-preta. Pelotas: Embrapa Clima Temperado, 2004. p.37-42. (Documento, 122)

ANTUNES, L.E.C.; CHALFUN, N.N.J.; REGINA, M. de A.; DUARTE FILHO, J. Fenologia e produção de variedades de amora-preta nas condições do planalto de Poços de Caldas. Revista Brasileira de Fruticultura, Jaboticabal, v.22, n.1, p.89-95, 2000a.

ANTUNES, L. E. C. ; CHALFUN, N. N. J. ; REGINA, M. de A. Propagação de cultivares de amoreira-preta através de estacas lenhosas. Revista Brasileira de Fruticultura, Jaboticabal, v. 22, n. 2, p. 195-199, 2000b.

ANTUNES, L.E.C.; CHALFUN, N.N.J.; REGINA, M. de A. Blossom and ripening periods of blackberry varieties in Brazil. Journal American Pomological Society, Massachusetts, v.54, n.4, p.164-168, 2000c.

CLEMENT, C.R.; BOVI, M.L.A. Padronização de medidas de crescimento e produção em experimento com pupunheiras para palmito. Acta Amazonica, Manaus, v.30, n.3, p. 349-362. 2000. 
CRANDALL, P.C. Bramble production: the management and marketing of raspberries and blackberries. New York: The Haworth Press. 1995. 213 p.

FACHINELLO, J.C.; HOFFMANN, A.; SANTOS, A.M. dos. Amoreira-preta, framboesa e mirtilo: pequenos frutos para o sul do Brasil. In: CONGRESSO BRASILEIRO DE FRUTICULTURA, 13., 1994, Salvador. Resumos... Salvador: Sociedade Brasileira de Fruticultura, 1994. v.3, p.989-990.

HOFFMANN, A.; PAGOT, E.; PALTRONIERI, P.; SANHUEZA, R.M.V. Pequenas frutas na região de Vacaria, RS: um breve histórico. In: SEMINÁRIO BRASILEIRO SOBRE PEQUENAS FRUTAS, 3., 2005, Vacaria. Anais... Bento Gonçalves-RS: Embrapa Uva e Vinho, 2005. v.1, p.11-14.

HULL, J.W. Thornless blackberries for the home garden. Washington: Northeastern Region Agricultural Research Service, 1975. 8p. (Home and Garden Bulletin, 207).

MACHADO, A.A.; CONCEIÇÃO, A.R. Sistema de análise estatística para Windows: Winstat. Versão 2.0. Pelotas: UFPel, 2003.
RASEIRA, M.C.B.; SANTOS, A.M.; BARBIERI, R.L. Classificação botânica, origem e cultivares. In: ANTUNES, L.E.C.; RASEIRA, M. do C.B. Aspectos técnicos da cultura da amora-preta. Pelotas: Embrapa Clima Temperado, 2004. p.17-28. (Documentos, 122)

SHOEMAKER, J.A. Small fruit culture. Westport: AVI Publ., 1978. p.188-250.

SOUSA, H.U. de. Efeito da composição e doses de superfosfato simples no crescimento e nutrição de mudas de bananeira (Musa sp.) cv. Mysore obtidas por cultura de meristemas. 1994. $75 \mathrm{f}$. Dissertação (Mestrado)-Universidade Federal de Lavras, Lavras, 1994.

STRIK, B.C.; CLARK, J.R.; FINN, C.E.; BANADOS, M.P. Worldwide blackberry production. Hortechnology. Alexandria, v.17, n. 2, p. 205-213, 2007.

TAKEDA, F. Winter pruning affects yield components of 'Black Satin' eastern thornless blackberry. Hortscience, Alexandria, v. 37, n. 1, p. 101-103, 2002. 